Document downloaded from:

http://hdl.handle.net/10251/68175

This paper must be cited as:

Barkouti, A.; Turchiuli, C.; Carcel Carrión, JA.; Dumoulin, E. (2013). Milk powder agglomerate growth and properties in fluidized bed agglomeration. Dairy Science and Technology. 93(4-5):523-535. doi:10.1007/s13594-013-0132-7.

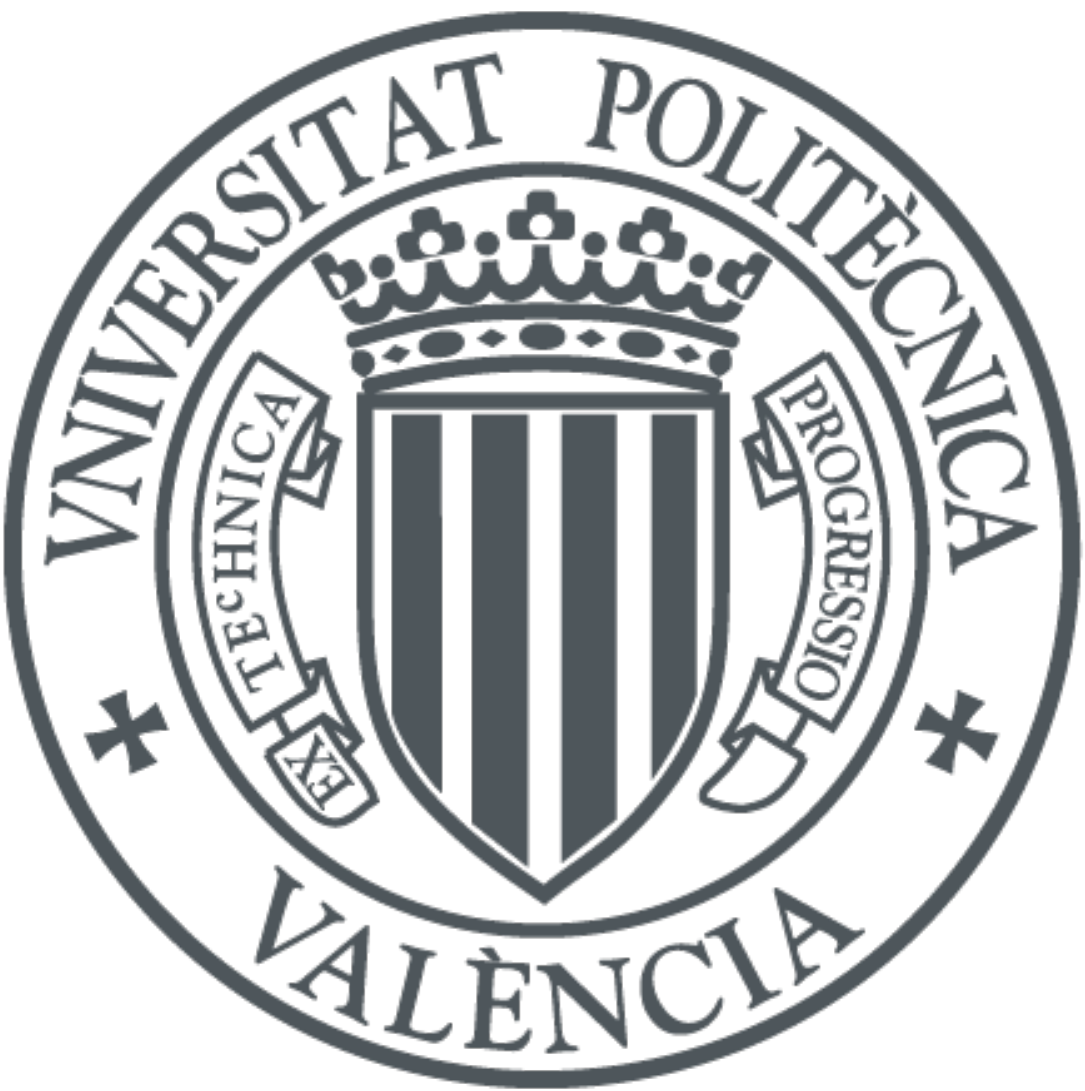

The final publication is available at

https://dx.doi.org/10.1007/s13594-013-0132-7

Copyright Springer Verlag (Germany)

Additional Information 


\title{
Milk powder agglomerate growth and properties in fluidized bed agglomeration
}

\author{
A. Barkouti \& C. Turchiuli \& J. A. Carcel \& E. Dumoulin
}

\begin{abstract}
Fluidized bed agglomeration is used to produce large and porous dry agglomerates with improved instant properties. Water (or binder solution) is sprayed in the fluidized bed of particles to render their surface sticky. The agglomerate growth results from the repetition of different steps (wetting of the particle surface, particles collision and bridging, and drying) and depends on the processing conditions and product properties. In this work, skim and whole milk powders were fluidized in hot air and agglomerated by spraying water in a bench-scale batch fluidized bed. The aim was to study the impact of the sprayed water flow rate (0-5.5 g.min $\left.{ }^{-1}\right)$, particle load (300-400 g), initial particle size (200-350 $\mu \mathrm{m}$ ), and composition (skim-whole milk) on the growth mechanisms and on the properties of the agglomerates obtained. Powder samples were regularly taken in the fluidized bed during agglomeration and characterized for the size, size distribution, and water content. Whatever the conditions tested, the size increase and the evolution of the particle size distribution during agglomeration were found to mainly depend on the relative amount of water sprayed in the particle bed. Agglomeration occurred in two stages, with first the rapid association of initial particles into intermediate structures, and second, the progressive growth of porous agglomerates. In any case, agglomeration allowed improving instant properties of the milk powder.
\end{abstract}


Keywords Agglomeration · Fluidized bed · Growth mechanism • Powder properties

\section{Nomenclature}

\begin{tabular}{lll}
\hline$a_{\mathrm{w}}$ & Water activity & - \\
$d_{50}$ & Median mass diameter & $\mu \mathrm{m}$ \\
$D$ & Mean diameter of size class & $\mu \mathrm{m}$ \\
$t$ & Time & $\mathrm{min}$ \\
$T_{\mathrm{b}}$ & Air temperature in fluidized bed & ${ }^{\circ} \mathrm{C}$ \\
$w$ & Water content in 100 g dry matter & $\%$ \\
$w_{0}$ & Water content at $t=0$ of spraying & $\%$ \\
$W$ & Weight of sprayed water & $\mathrm{g} \mathrm{g.kg}$ \\
$Y$ & Water content in dry air & -1 \\
$\rho$ & Density & $\mathrm{kg} . \mathrm{m}^{-}$ \\
\hline
\end{tabular}

\section{Introduction}

Food powders are largely produced and used as ingredients in many food formulations or consumed as end products such as milk powder, instant coffee, sugar, infant formulas, etc. The importance of food powders production and consumption is mainly linked to the convenience offered by powders, especially regarding their chemical and microbiological stability due to reduced water content, which also leads to reduced mass and easier and more economic transport (Forny et al. 2011). But powders must have good end-use properties, and an agglomeration step is often necessary to produce instant products dispersing and/or dissolving quickly in liquids (water, milk) with a good flowability.

Different agglomeration technologies are available. In particular, fluidized bed agglomeration of individual particles $(100-200 \mu \mathrm{m})$ is used to produce large and porous dry agglomerates $(700 \mu \mathrm{m}-1 \mathrm{~mm})$ with modified properties such as density, flowability, mechanical resistance, and instant properties. Initial particles are fluidized in rising hot air and sprayed at their surface with a liquid (binder solution or water) to render them locally sticky. Collisions between fluidized wet "sticky" particles allow adhesion with the formation of either liquid or sinter bridges through viscous flow in the case of amorphous powders (Fries et al. 2010). The simultaneous drying by the hot fluidization air ensures the consolidation of the new structure formed. Drying must be controlled to avoid collapse of the particle bed (insufficient drying) or insufficient wetting leading to no agglomeration (too much drying). The repetition of the different steps of wetting, collision, adhesion, drying, and mixing leads to the progressive growth of agglomerates in which initial particles still can be identified. Fluidized beds are characterized by efficient mixing and intensive heat and mass transfer. In top of sprayed fluidized beds, it was shown that, despite the efficient mixing of particles, three thermal regions can be identified (the wetting active zone, the isothermal zone, the heat transfer zone), with size depending 
on the operating parameters. Agglomeration is thought to occur mainly in the wetting active zone where temperature and humidity conditions allow having sticky particles (Jimenez et al. 2006; Heinrich et al. 2003; Maronga and Wnukowski 1997, 1998). Fluidized bed agglomeration is a complex process in which many parameters interact influencing the growth kinetics and the structure and properties of the agglomerates obtained. Some are linked to the product (composition, size, size distribution, "surface reactivity"), others are linked to the equipment (geometry of the chamber, way of introducing the sprayed liquid, air disperser) and to the process. Especially, the spraying rate of the liquid, the droplet size, the flow rate, temperature and humidity of the fluidizing air, and the particle load may have an important effect on the agglomeration process. Several studies have shown that the increase of the liquid spraying rate (Niskanen et al. 1990; Dewettinck et al. 1998) or of the sprayed droplets size (Waldie et al. 1987) leads to produce larger agglomerates. And an increase of the initial particle load may make fluidization inefficient and lead to large clusters due to local wetting and to an excess of particles not well fluidized.

In this work, milk powder was used as a model food powder. Milk particles are complex mixtures of carbohydrates, proteins, minerals, and fats. During fluidized bed agglomeration with water spraying in hot air, amorphous carbohydrates are likely to undergo glass transition due to the plasticizing effect of water wetting locally the particles. If the surface viscosity becomes locally lower than $10^{8} \mathrm{~Pa}$.s, the critical viscosity corresponding to sticky particles, sinter bridges may be formed when particles collide (Palzer 2011). At the same time, fats, known to be overrepresented in the first layers of the particle surface, even in skim milk particles (Kim et al. 2009; Murrieta-Pazos et al. 2011), may melt and also contribute to adhesion between colliding particles. Despite agglomeration being an important step in the production of "instant milk powder" (Banjac et al. 1998, 2009; Koga et al. 1989; Neff and Morris 1968), some knowledge gaps still exist especially concerning the mechanisms of agglomerate formation and their relation with initial particle properties and process conditions.

The aim of this study was to investigate the influence of some process (sprayed water flow rate, particle load) and product parameters (composition, initial particle size) on the growth of skim (SMP) and whole (WMP) milk powder agglomerates in order to understand the mechanisms involved during wet agglomeration in fluidized bed and their impact on the physical and handling properties of agglomerates and powders.

\section{Materials and methods}

Skim and whole milk powders (Table 1), provided by Lactalis (France), were sieved between 100 and $250 \mu \mathrm{m}$ (Analysette 3 Spartan, Fritsch, Ge-200 g, $4 \mathrm{~min}$, amplitude of vibration $2.5 \mathrm{~mm}$ ) to get initial particles with similar monomodal particle size distribution. After sieving, they had a median diam- eter of 198 and $235 \mu \mathrm{m}$, respectively. For skim milk powder, a second size fraction with a median diameter of $350 \mu \mathrm{m}$ (sieved size fraction $>250 \mu \mathrm{m}$ ) was also prepared. Their initial water content was 4.9 and $5.3 \mathrm{~g} .100 \mathrm{~g}^{-1}$ dry matter, respectively, for SMP and WMP. 
Table 1 Bulk composition ( $\%$ w/w) of skim and whole milk powders (data from provider)

\begin{tabular}{lll}
\hline & Skim milk powder (SMP) & Whole milk powder (WMP) \\
\hline Carbohydrates & 53 & 40 \\
Proteins & 37 & 25 \\
Fats & $<1$ & 30 \\
Minerals & 9 & 5 \\
\hline
\end{tabular}

Agglomeration trials were performed in a bench-scale batch fluidized bed granulator (UniGlatt, Glatt, Ge) (Fig. 1). The conditions tested are summarized in Table 2. They were chosen in order to have, in any case, at the end of the trial, the same ratio between the total mass of water sprayed and the mass of milk particle in the bed, e.g., $55 \pm$ $1 \mathrm{~g} .100 \mathrm{~g}^{-1}$ particle. For trials 2 and 3 corresponding respectively to a smaller spraying flow rate and a larger particle load, this led to trials with different spraying durations (e.g., 38 and $40 \mathrm{~min}$, respectively, compared to $30 \mathrm{~min}$ for other trials).

For all the trials, the hot air flow rate was similar and kept constant $\left(75 \mathrm{~kg}^{-\mathrm{h}^{-1}}\right)$, allowing an initial fluidized bed height of about $26 \mathrm{~cm}$ (about $1 \mathrm{~cm}$ below the nozzle liquid tip), and ensuring a good fluidization of the particles along the trial, but the powder bed height was not controlled.

At first, initial particles were heated up (12-20 min) in the fluidizing air to reach a stable bed temperature $T_{\mathrm{b}}$ of $55 \pm 1^{\circ} \mathrm{C}$. Then, distilled water $\left(20^{\circ} \mathrm{C}\right)$ was top sprayed using a twofluid nozzle (type 970, Schlick) with a relative air pressure of 1 bar (spraying air flow rate inferior to $1 \mathrm{~kg} \cdot \mathrm{h}^{-1}$ ). The sprayed water drops had a median volume diameter $d_{50}$ of about $39 \mu \mathrm{m}$ for the water flow rates tested (Spraytec, Malvern, France). The pulverization of water caused a decrease of the bed temperature $T_{\mathrm{b}}$ of about 10 to $15^{\circ} \mathrm{C}$ (Fig. 2). In order to have the same constant bed temperature $T_{\mathrm{b}}=49 \pm 1{ }^{\circ} \mathrm{C}$ during the pulverization for all the trials, the inlet air temperature was adjusted along the trials.

Additional experiments were carried out in similar conditions with both skim and whole milk powders fluidized in hot air without water pulverization to check the effect of heating in the agglomeration process (i.e., melting of some surface components).

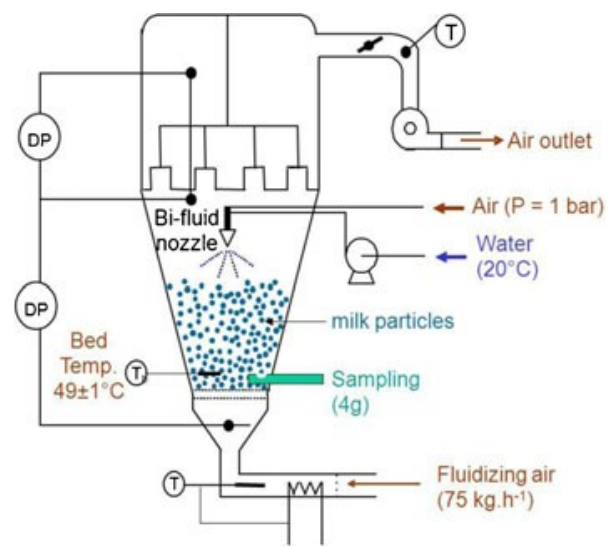

Fig. 1 Batch fluidized bed granulator (UniGlatt) 


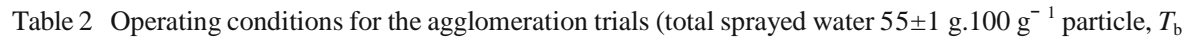
$49 \pm 1{ }^{\circ} \mathrm{C}$, air flow rate $75 \mathrm{~kg} \cdot \mathrm{h}^{-1}$ )

\begin{tabular}{|c|c|c|c|c|c|c|}
\hline $\begin{array}{l}\text { Trial } \\
\text { no. }\end{array}$ & Powder & $\begin{array}{l}\text { Load } \\
\text { (g) }\end{array}$ & $\begin{array}{l}d_{50} \\
(\mu \mathrm{m})\end{array}$ & $\begin{array}{l}\text { Water flow rate } \\
\left(\text { g.min }{ }^{-1} \text { ) }\right.\end{array}$ & $\begin{array}{l}\text { Spraying duration } \\
\text { (min) }\end{array}$ & $\begin{array}{l}\text { Sprayed water } \\
\text { (g) }\end{array}$ \\
\hline 1 & SMP & 300 & $198 \pm 6$ & 5.64 & 30 & 169.7 \\
\hline 2 & & 300 & & 4.33 & 38 & 170.7 \\
\hline 3 & & 400 & & 5.48 & 40 & 219.2 \\
\hline 4 & & 300 & $350 \pm 4$ & 5.43 & 30 & 163.1 \\
\hline 5 & WMP & 300 & $230 \pm 7$ & 5.5 & 30 & 165 \\
\hline
\end{tabular}

Bold characters are for the parameter varied in the trial

During the trials, samples (approximately $4 \mathrm{~g}$ ) were regularly taken in the bottom of the fluidized bed (6 $\mathrm{cm}$ above the air disperser) at preset times ( $\approx$ each $5 \mathrm{~min}$ ) with a perforated tube (Turchiuli et al. 2012). The final agglomerated powder was immediately recovered into hermetic jars (without drying/cooling stage in order to avoid breakage of the agglomerates due to attrition) and stored at ambient temperature before analysis within the following $24 \mathrm{~h}$.

Particle size distribution was obtained by manual sieving (2 g, 2 min) using a series of 14 sieves (diameter $5 \mathrm{~cm}$ ) with openings between 100 and 2,000 $\mu \mathrm{m}$ according to a $2^{1 / 3}$ geometric progression. Powder water content was measured by oven drying $\left(105^{\circ} \mathrm{C}, 1 \mathrm{~g}, 24 \mathrm{~h}\right)$. Final powder wettability was estimated by measuring the time required for $5 \mathrm{~g}$ of powder to completely sink in $100 \mathrm{~mL}$ of water $\left(20^{\circ} \mathrm{C}\right)$ contained in a $400-\mathrm{mL}$ beaker with a $70-\mathrm{mm}$ diameter and 135 mm height. Bulk and tapped densities were obtained measuring the volume occupied by a given mass of powder in a 25-mL test tube before and after 1250 falls (density tester, Varian, France). Flowability was estimated measuring the time required for $10 \mathrm{~g}$ of powder to flow out of a calibrated funnel (AFNOR NFB 35032). The water activity was measured by capacitance hygrometer method (Thermoconstanter, Novasina).

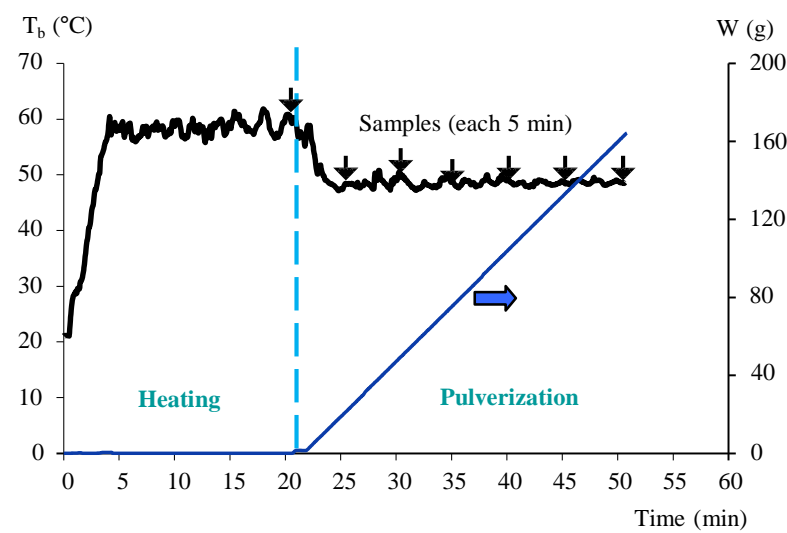

Fig. 2 Evolution of the bed temperature $T_{\mathrm{b}}$ and weight of water sprayed $W$ during an agglomeration trial 


\section{Results}

When fluidizing skim and whole milk particles in hot air without spraying water, no evolution of the particle size distribution was observed during at least 50 min. While for fat filled milk powders some stickiness may be attributed to surface fat, for the two powders tested, the agglomeration process required spraying water on the particle surface to increase its adhesiveness. And, in the studied conditions, the growth of milk agglomerates may be attributed mainly to carbohydrates.

\subsection{Repeatability of agglomeration trials}

Trial 1 with skim milk powder was repeated three times (1, 1a, and 1b), keeping the same operating conditions, in order to check the influence of "not controlled" parameters on the evolution of the particle size distribution and water content of samples. Especially, the relative humidity $\mathrm{HR}_{\mathrm{air}}$ and water content $Y$ of the fluidizing air taken from the outside were not controlled and may vary from one trial to another (Table 3). The sprayed water flow rate also slightly varied despite the same settings of the pump, and the manual regulation of the bed temperature $T_{\mathrm{b}}$ led to some differences ( \pm 1 to $2^{\circ} \mathrm{C}$ ) between each trial.

The evolution of the median diameter $d_{50}$ of the samples was similar for the three trials (Fig. 3a), but the evolution of the water content (Fig. 3b) was slightly different for trial 1a. The lower water content of the samples in this case may be explained by the lower water content $Y$ of the drying air (5 g. $\mathrm{kg}^{-1}$ to be compared to 7 g. $\mathrm{kg}^{-1}$ for

trials 1 and $1 \mathrm{~b})$ and the higher bed temperature $\left(50.7^{\circ} \mathrm{C}\right.$ compared to 48.2 and $49.3^{\circ} \mathrm{C}$ ) (Table 3 ) corresponding both to more efficient drying conditions leading to drier agglomerates.

From these results, it seems that repeatability concerning agglomerate growth was good (sufficient) and made it possible to compare between the trials performed in different operating conditions. But results concerning the water content will have to be considered carefully since subjected to some variation due to the "not controlled" parameters.

\subsection{Influence of process and products parameters on agglomerates growth}

Both the kinetics and mechanism of agglomerates growth were studied for different sprayed water flow rate and initial particle load, size, and composition.

Table 3 Ambient air temperature $T_{\text {air }}$, relative humidity $\mathrm{RH}_{\text {air }}$, water content $Y$, and inlet temperature $T_{\text {hot air }}$; bed temperature $T_{\mathrm{b}}$ and water flow rate measured during agglomeration trials $1,1 \mathrm{a}$, and $1 \mathrm{~b}$

\begin{tabular}{lllllll}
\hline Trial & $T_{\text {air }}\left({ }^{\circ} \mathrm{C}\right)$ & $\mathrm{RH}_{\text {air }}(\%)$ & $Y\left(\mathrm{~g} . \mathrm{kg}^{-1} \mathrm{dry}\right.$ air $)$ & $T_{\text {hot air }}\left({ }^{\circ} \mathrm{C}\right)$ & $T_{\mathrm{b}}\left({ }^{\circ} \mathrm{C}\right)$ & Water flow rate $\left(\mathrm{g} \cdot \mathrm{min}^{-1}\right)$ \\
\hline 1 & 14 & 69 & 7 & $71.5-68$ & 48.2 & 5.64 \\
$1 \mathrm{a}$ & 17 & 44 & 5 & 70 & 50.7 & 5.63 \\
$1 \mathrm{~b}$ & 22 & 42 & 7 & $70-65$ & 49.3 & 5.64 \\
\hline
\end{tabular}



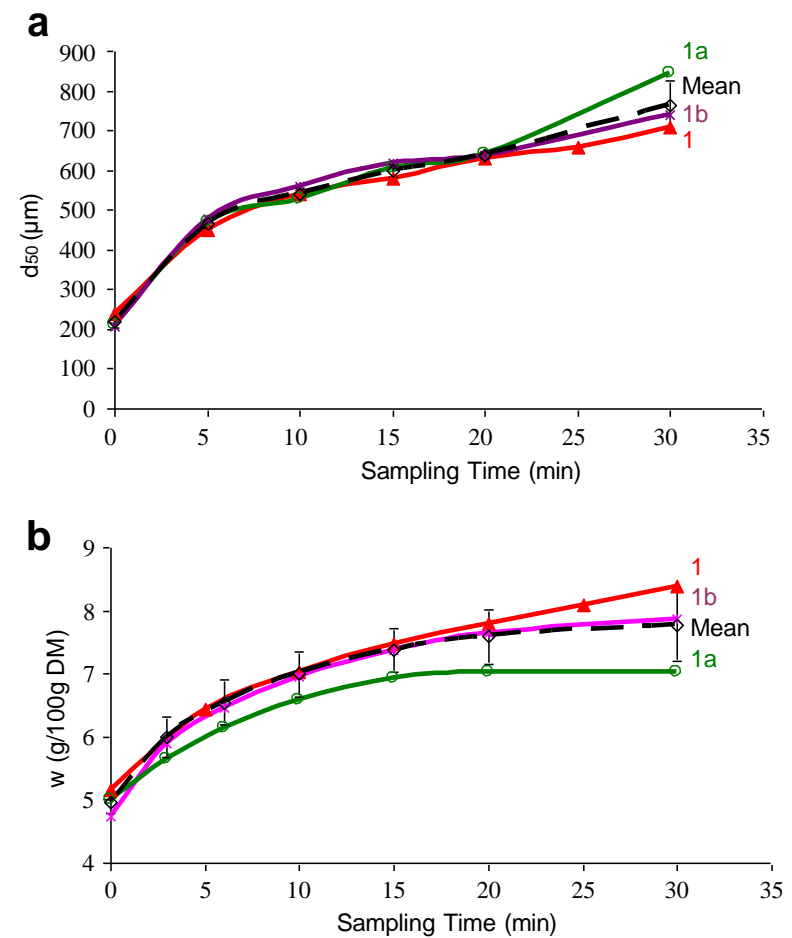

Fig. 3 Evolution of the mass median diameter (a) and water content (b) of samples for agglomeration trials $1,1 \mathrm{a}$, and $1 \mathrm{~b}$, and mean value with standard deviation

\subsubsection{Growth kinetics}

Figure 4 depicts the evolution of the median diameter $d_{50}$ and relative water content increase $\left(w-w_{0}\right) / w_{0}$ of the samples taken each 5 min during the pulverization stage. For all the conditions tested, similar evolution were observed with, during the first minutes, a rapid increase of the median diameter and particle water content, and then a slow down followed, in some cases, by a stabilization especially for the water content increase. This evolution is typical for soluble particles (Jimenez 2007).

Comparing with trial 1, the decrease of the water flow rate (trial 2) or the increase of the particle load (trial 3) decreased the growth kinetics and led to a lower increase of the moisture content of the powder (Fig. 4). In both cases, the ratio between the quantity of water sprayed per unit time and the mass of particle in the fluidized bed, corresponding to a specific rate of wetting, is decreased (from $19.10^{-3}$ to about $14.10^{-3}$ g water.g $^{-1}$ solid.min ${ }^{-1}$ ). At a given time, less water is therefore available at the surface of each particle to contribute to its stickiness and to the formation of bridges.

When increasing the size of the initial particles (trial $4-350 \mu \mathrm{m}$ instead of $198 \mu \mathrm{m}$ for trial 1), no modification was observed in the evolutions of the relative water content increase, and the evolution of the median diameter had a similar shape with a constant gap upward corresponding to the initial size difference (about $150 \mu \mathrm{m})$ (Fig. 4). As a consequence, the evolution of the size increase $\left(d_{50}-d_{50}\right)$ with time was similar for trials 1 and 4 despite the different size ratio between the 

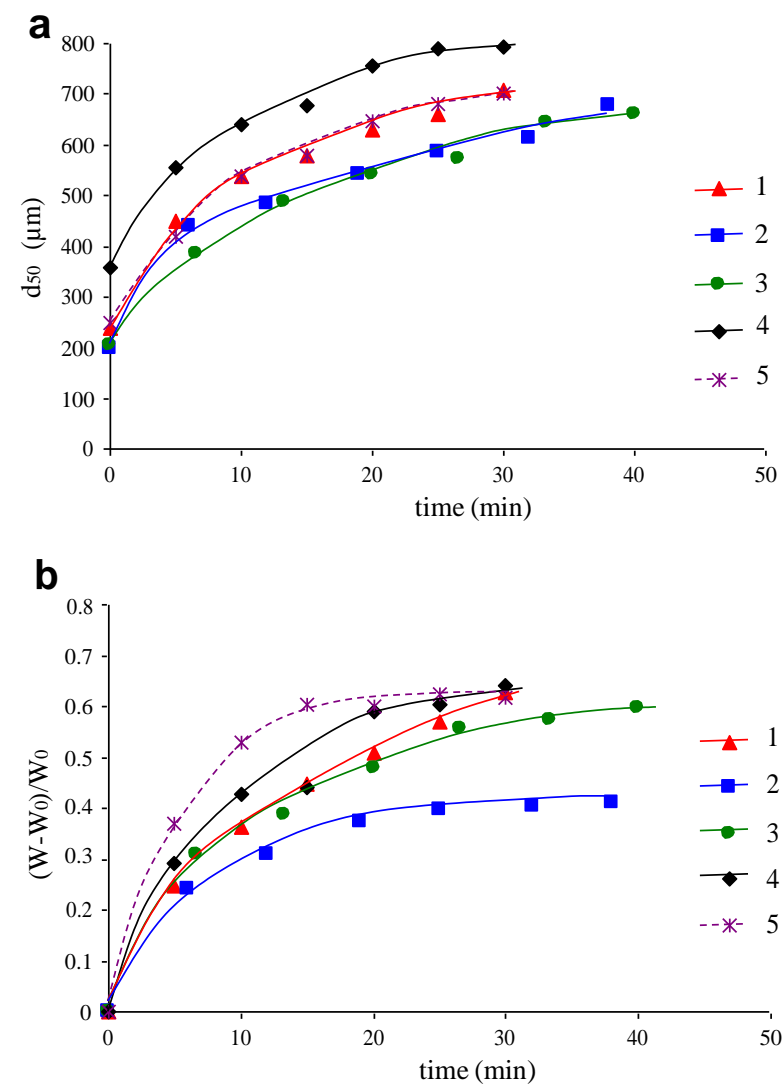

Fig. 4 Evolution of the mass median diameter $d_{50}$ (a) and relative water content increase $\left(\left(W-W_{0}\right) / W_{0}\right)$ (b) during agglomeration

sprayed liquid drops and the particles (39/198 $=0.2$ for trial 1 compared to 39/350= 0.11 for trial 4) (Fig. 5). In this range of variation, this parameter does not control the growth kinetics of agglomerates.

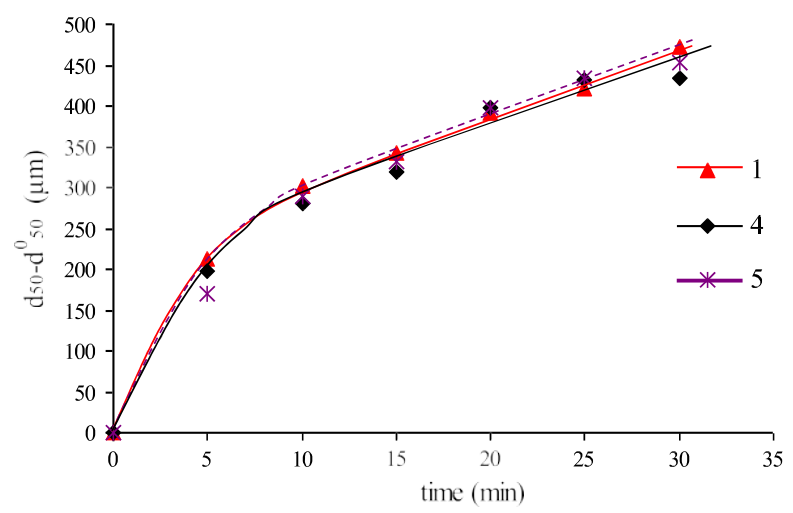

Fig. 5 Evolution of the median diameter increase $\left(d_{50}-d_{0}^{0}\right)$ of the samples with time 
To end, when agglomerating whole milk particles (trial 5) instead of skim milk particles (trial 1) in similar conditions, no difference was observed in the evolution of the median diameter with time and only a small gap upward appeared in the evolution of the water content increase (Fig. 4). This gap may be attributed to the higher hygroscopicity of whole milk powder compared to skim milk powder. But, since no difference occurred in the growth kinetics, it seems that this has no influence on the development of the surface stickiness attributed to the presence of carbohydrates. Despite a different bulk composition, skim and whole milk powders may have a close surface composition (Murrieta-Pazos et al. 2011), and therefore a similar surface "reactivity" regarding agglomeration. This reactivity seems to be linked to the presence of lactose that was found to be the key component in the state diagram of milk regarding glass transition (Vuataz 2002).

\subsubsection{Growth mechanism}

The growth mechanism of agglomerates was investigated through the evolution of the particle size distribution with the spraying time (Fig. 6a). For all the trials, similar

a

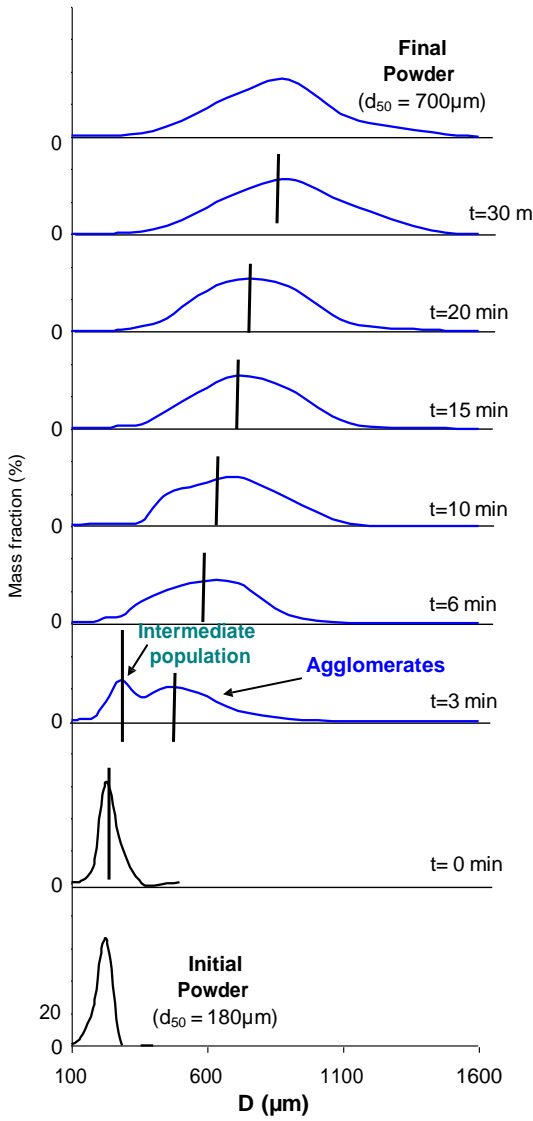

b
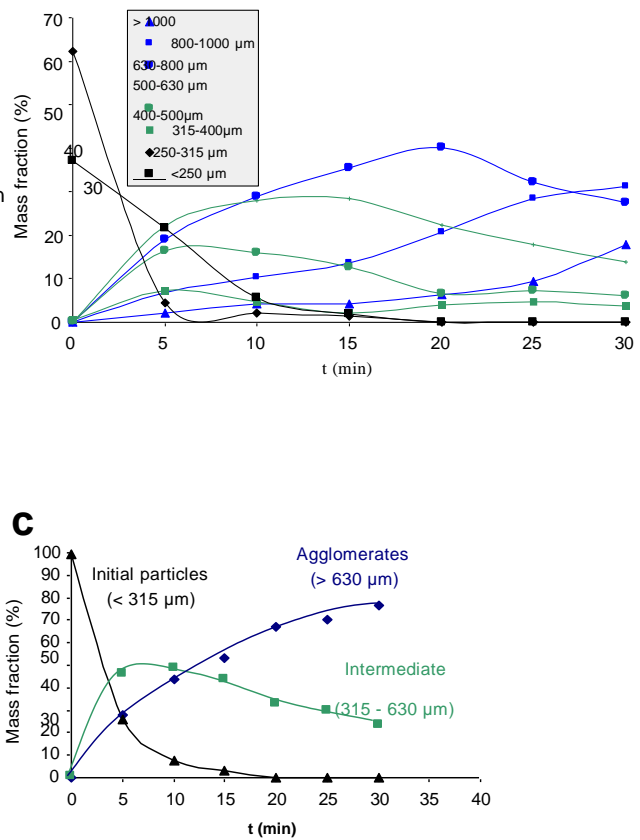

Fig. 6 Evolution of the particle size distribution (a), of the mass fraction in each size class (b), and of the mass fraction of the three populations (c) with time during agglomeration trials 
Table 4 Properties of the three initial powders and of the five final powders agglomerated with the same quantity of water per unit mass of particle (55 $\mathrm{g}$ water. $100 \mathrm{~g}^{-1}$ particle)

\begin{tabular}{|c|c|c|c|c|c|c|c|c|}
\hline \multirow[t]{2}{*}{ Powder } & \multicolumn{2}{|l|}{ Initial } & & \multicolumn{5}{|c|}{ Agglomerated } \\
\hline & WMP & SMP & & SMP & & & & WMP \\
\hline Trial no. & - & - & - & 1 & 2 & 3 & 4 & 5 \\
\hline$d_{50}(\mu \mathrm{m})$ & $230 \pm 7$ & $198 \pm 6$ & $350 \pm 4$ & 700 & 650 & 640 & 874 & 672 \\
\hline Wettability (s) & $>2 \mathrm{~h}$ & $>1 \mathrm{~h}$ & $>1 \mathrm{~h}$ & \multicolumn{4}{|c|}{$<4 \mathrm{~s}$} & $29 \mathrm{~s}$ \\
\hline$\rho_{\text {bulk }}\left(\mathrm{kg} . \mathrm{m}^{-3}\right)$ & $500 \pm 18$ & $510 \pm 7$ & $400 \pm 2$ & \multicolumn{5}{|c|}{$240 \pm 14$} \\
\hline$\rho_{\text {tapped }}\left(\mathrm{kg} \cdot \mathrm{m}^{-3}\right)$ & $570 \pm 17$ & $580 \pm 7$ & $460 \pm 7$ & \multicolumn{5}{|c|}{$260 \pm 19$} \\
\hline Flowability & Very bad & \multicolumn{7}{|c|}{ Very good } \\
\hline$w(\%)$ & 5.3 & $\sim 5$ & 4.5 & 7.3 & 6.8 & 7.0 & 6.0 & 5.0 \\
\hline
\end{tabular}

evolutions were obtained with an intermediate population $(\sim 250 \mu \mathrm{m})$ appearing within about the first 3 min of the agglomeration process and then disappearing progressively. At the same time, the main population of agglomerates grew from an initial size of about $400 \mu \mathrm{m}$ to a final $d_{50}$ of about $700 \mu \mathrm{m}$ (Table 4). Moreover, the evolution of the mass fraction in each size class with time (Fig. 6b) showed three typical evolutions corresponding to the three populations. The first population corresponding to the initial particles was characterized by a fast decrease in mass percentage during the first minutes of water pulverization (Fig. 6c). As the proportion of initial particles decreased, the proportion of intermediate particles increased rapidly during the first minutes and then decreased progressively while the third fraction, corresponding to agglomerates, increased progressively with a slow down when almost all the initial particles had disappeared.

The optical observation of skim and whole milk agglomerates during their growth showed that agglomerates develop a porous structure with irregular shape (Fig. 7). This
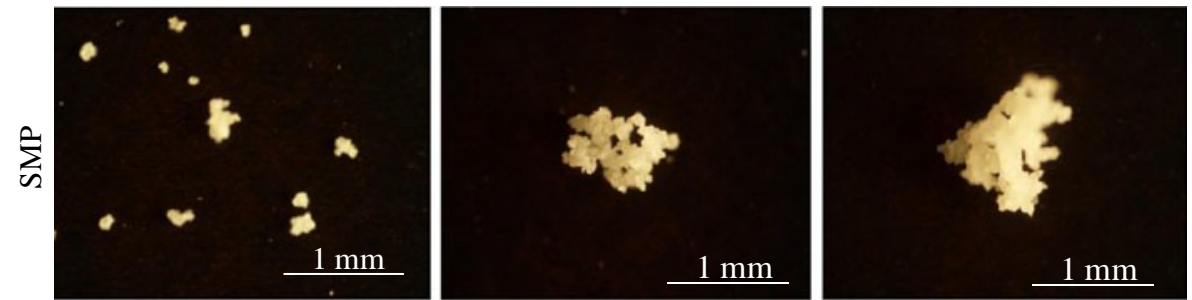

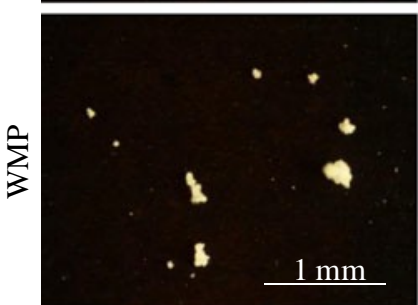

Initial powder

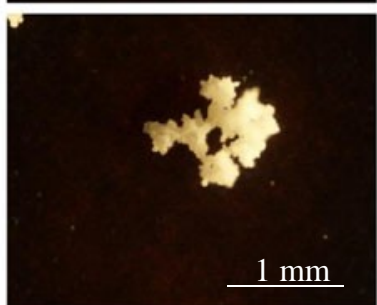

$\mathrm{t}=15 \mathrm{~min}$

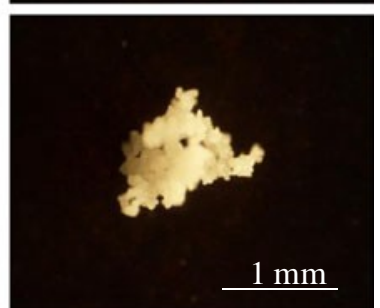

Final powder

Fig. 7 Initial particles, intermediate and final agglomerate (optical microscope) for skim (trial 1) and whole (trial 5) milk particles agglomeration 


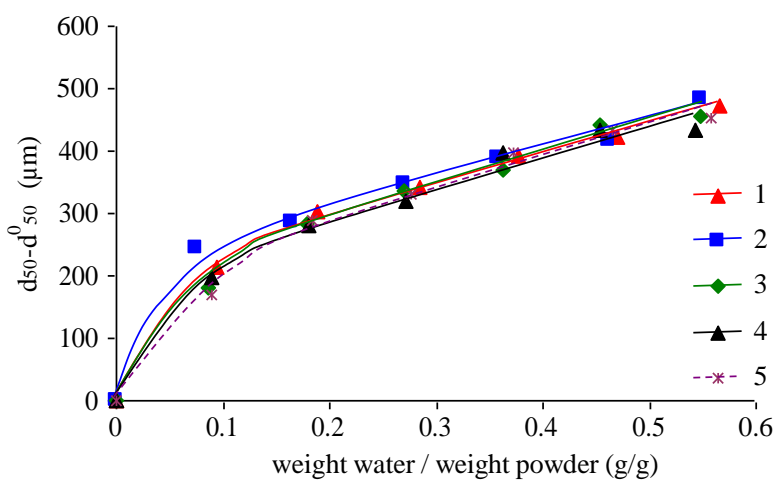

Fig. 8 Evolution of the median diameter increase according to the ratio between the weight of sprayed water and the weight of particle

is consistent with a class by class growth mechanism with first, the association of initial particles into rather compact intermediate structures, and second, the association of these structures into larger and larger loose agglomerates.

\subsection{Properties of final powders}

Whatever the conditions tested for the same quantity of water sprayed per unit mass of particle (e.g., $55 \mathrm{~g}$ water.100 g ${ }^{-1}$ particle), agglomerates obtained had similar diameters (e.g., comprised between 640 and $700 \mu \mathrm{m}$ for $200 \mu \mathrm{m}$ initial particles) (Table 4). Compared to the initial powder requiring several hours to sink into water, all the agglomerated powders had a very good wettability and were nearly instant. This was probably due to their larger size and more porous structure (Fig. 7) also leading to a significant decrease of their bulk and tapped density (factor 2). The flowability of the initial skim milk powders was very good and was not modified after agglomeration despite the irregular shape of agglomerates. For the whole milk powder, flowability was significantly improved after agglomeration. The powder water content was increased from 4.5 to about $7 \%$ since, in order to avoid breakage due to attrition, agglomerates were collected immediately after stopping spraying without the usual drying/cooling step.

\section{Discussion}

The sprayed water flow rate (trial 2) and the initial particle load (trial3) were found to have an influence on the agglomerates growth kinetics since modifying the quantity of water available at the particle surface. But this may also be due to changes in the growth mechanism, especially when changing the particle load in the chamber, since with a higher particle load, the higher particle density may lead to a higher collision probability. When representing the median diameter increase $\left(d_{50}-d^{0}{ }_{50}\right)$ according to the ratio between the weight of sprayed water and the weight of particle, very similar curves were obtained whatever the conditions tested (Fig. 8). In these conditions, the 
size growth mechanism seems therefore to be mainly controlled by the quantity of water sprayed. And a critical ratio between the weight of water sprayed and the weight of particle corresponding to the transition between the constant rate growth phase and the decreasing rate growth phase can be determined. This critical ratio is about $0.1 \mathrm{~g}$ water/g particle. It is reached in the early minutes of the process and seems to correspond to the disappearing of the initial particles. This is in agreement with the two stages of growth mechanism suggested here and already observed during wet agglomeration of milk powder in vibro-fluidized bed (Banjac et al. 1998) or of durum wheat semolina in low shear mixer (Saad et al. 2011): first, the initial particles associate into small intermediate structures also called "nuclei" from which larger agglomerates are progressively built.

\section{Conclusion}

Fluidized bed agglomeration of milk powder generated significant changes in particle size distribution of the powder and on the particle structure, and improved the powder handling properties (wettability, flowability).

The bulk composition of the milk powder (skim or whole milk) did not influence the agglomeration kinetics. Particle stickiness, attributed to the presence of lactose at the particle surface, developed similarly for both skim and whole milk powders. In the conditions tested, the size increase mainly depended on the relative weight between the water sprayed and the particle load. The sprayed water flow rate and the particle load only influenced the growth kinetics but not the growth mechanism with, in any case, two stages corresponding respectively to the association of initial particles into intermediate structures (315-630 $\mu \mathrm{m})$, and then, the progressive formation of larger agglomerates $(700 \mu \mathrm{m})$. The transition between both stages corresponded to a critical value of the relative weight of water sprayed of $0.1 \mathrm{~g}$ water/g particle. This growth mechanism may have an influence on the agglomerates structure that may be different for skim and whole milk agglomerates leading to a different behavior during later use. The relationship between the growth mechanism and the agglomerate structure and the consequences on the agglomerated powder properties have to be further investigated.

Acknowledgments This study is part of the PhD work of A. Barkouti in the scope of "Reactive Powder" project funded by the French National Agency for Research. It was performed in collaboration with Juan A. Carcel from the Universitat Politècnica de València (Spain) during a stay in AgroParisTech, Massy, thanks to the economic support of Ministerio de Educación of Spain (ref. PR201-0333).

\section{References}

Banjac M, Stakic M, Voronjec D (1998) Kinetics of agglomeration of milk powder in a vibro-fluidized bed. Proc. 11th International Drying Symposium (IDS'98), B: 998-1005.

Banjac M, Stamenić M, Lečić M, Stakić M (2009) Size distribution of agglomerates of milk powder in wet granulation process in a vibro-fluidized bed. Brazilian J Chem Eng 26:515-525

Dewettinck K, Deroo L, Messens W, Huyghebaert A (1998) Agglomeration tendency during top-spray fluidized bed coating with gums. Lebensm Wiss Technol 31:576-584 
Forny L, Marabi A, Palzer S (2011) Wetting, disintegration and dissolution of agglomerated water soluble powders. Powder Technol 206:72-78

Fries L, Dosta M, Antonyuk S, Heinrich S, Palzer S (2010) Moisture distribution in fluidized beds with liquid injection. Proc. 17th International Drying Symposium (IDS 2010), Magdeburg, Germany.

Heinrich S, Blumschein J, Henneberg M, Ihlow M, Mörl L (2003) Study of dynamic multidimensional temperature and concentration distributions in liquid-sprayed fluidized beds. Chem Eng Sci 58:5135-5160

Jimenez T (2007) Agglomération de particules par voie humide en lit fluidisé [Wet fluidized bed agglomeration of particles]. PhD, ENSIA, Massy, France.

Jimenez T, Turchiuli C, Dumoulin E (2006) Particles agglomeration in a conical fluidized bed in relation with air temperature profiles. Chem Eng Sci 61:5954-5961

Kim EH-J, Dong Chen X, Pearce D (2009) Surface composition of industrial spray-dried milk powder. J Food Eng 94:169-181

Koga S, Kobayashi T, Inoue I (1989) Drying and agglomeration of skim milk powder by a vibro-fluidized bed, heat transfer. Japan Res 18:1-8

Maronga SJ, Wnukowski P (1997) Establishing temperature and humidity profiles in fluidized bed particulate coating. Powder Technol 94:181-185

Maronga SJ, Wnukowski P (1998) The use of humidity and temperature profiles in optimizing the size of fluidized bed in a coating process. Chem Eng Sci 37:423-432

Murrieta-Pazos I, Gaiani C, Galet L, Cuq B, Desobry S, Scher J (2011) Comparative study of particle structure evolution during water sorption: skim and whole milk powders. Coll and Surf B Biointerfaces 87:1-10

Neff E, Morris HAL (1968) Agglomeration of milk powder and its influence on reconstitution properties. J Dairy Sci 51:330-338

Niskanen T, Yliruusi J, Niskanen M, Kontro O (1990) Granulation of potassium chloride in instrumented fluidized bed granulator-part I: effect of flow rate. Acta Pharm Fenn 99:13-22

Palzer S (2011) Agglomeration of pharmaceutical, detergent, chemical and food powders - similarities and differences of materials and processes. Powder Technol 206:2-17

Saad MM, Barkouti A, Rondet E, Ruiz T, Cuq B (2011) Study of agglomeration mechanisms of food powders: application to durum wheat semolina. Powder Technol 208:399-408

Turchiuli C, Smail R, Dumoulin E (2012) Fluidized bed agglomeration of skim milk powder: analysis of sampling for the follow-up of agglomerate growth. Powder Technol 238:161-168

Vuataz G (2002) The phase diagram of milk: a new tool for optimizing the drying process. Lait 82:485-500

Waldie B, Wilkinson D, Zachra L (1987) Kinetics and mechanisms of growth in batch and continuous fluidized bed granulation. Chem Eng Sci 42:653-665 